\title{
Publisher Correction: Sensitive mid-infrared detection in wide-bandgap semiconductors using extreme non-degenerate two-photon absorption
}

Dmitry A. Fishman, Claudiu M. Cirloganu, Scott Webster, Lazaro A. Padilha, Morgan Monroe, David J. Hagan and Eric W. Van Stryland

Correction to: Nature Photonics https://doi.org/10.1038/nphoton.2011.168, published online 7 August 2011.

In the version of Article originally published, a graphical handling error occurred, leading to the $y$-axis values and tick placement from Fig. 2a being duplicated in Fig. 2b. The correct panel b $y$-axis, ranging from $10^{0}-10^{3}$ (rather than $10^{-1}-10^{3}$ ) is shown below.

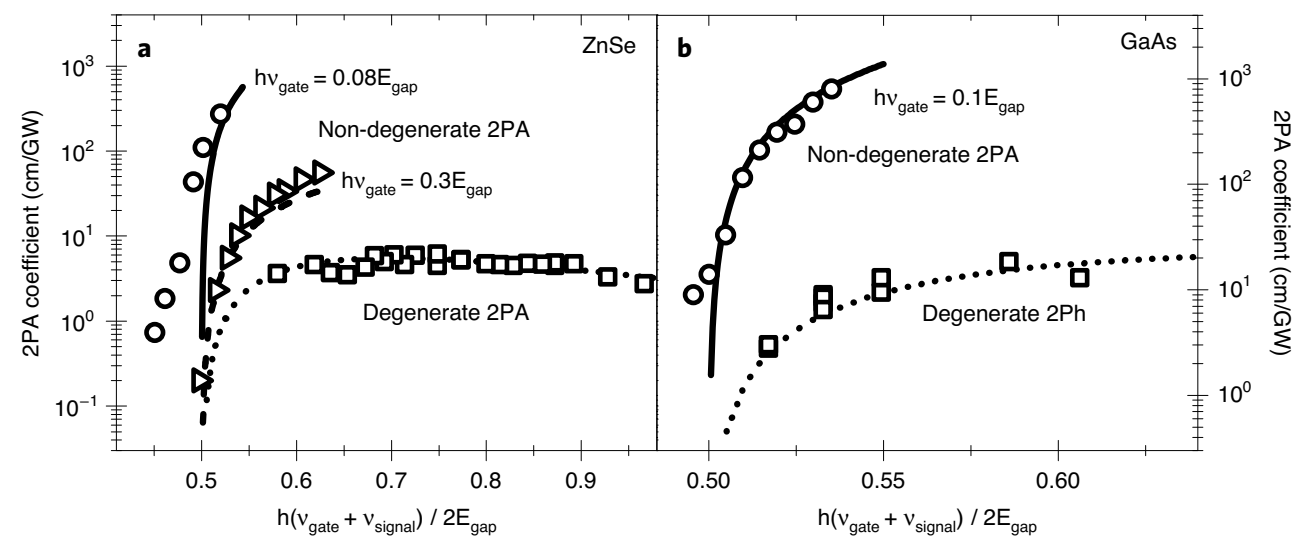

Fig. 2 | Corrected.

Published online: 3 December 2021

https://doi.org/10.1038/s41566-021-00930-8

( The Author(s), under exclusive licence to Springer Nature Limited 2021

\section{Addendum: Slow carrier relaxation in tin-based perovskite nanocrystals}

Linjie Dai D, Zeyu Deng, Florian Auras (D), Heather Goodwin, Zhilong Zhang D, John C. Walmsley, Paul D. Bristowe,

Felix Deschler and Neil C. Greenham (D)

Addendum to: Nature Photonics https://doi.org/10.1038/s41566-021-00847-2, published online 2 August 2021.

The authors wish to acknowledge the following highly relevant manuscript should have been cited in this Article:

Toso, S., Baranov, D., Giannini, C., Marras, S. \& Manna, L. Wide-angle X-ray diffraction evidence of structural coherence in CsPbBr ${ }_{3}$ nanocrystal superlattices. ACS Mater. Lett. 1, 272-276 (2019).

This manuscript describes how X-ray diffraction experiments and associated mathematical modelling and data analysis have previously identified and characterized a superlattice structure in colloidal perovskite nanocrystals. Further analysis of these structures is also described in this Article:

Toso, S. et al. Multilayer diffraction reveals that colloidal superlattices approach the structural perfection of single crystals. ACS Nano 15, 6243-6256 (2021).

Published online: 1 October 2021

https://doi.org/10.1038/s41566-021-00900-0

(C) The Author(s), under exclusive licence to Springer Nature Limited 2021 